\title{
Música como Recurso de Enfrentamento em Pacientes Oncológicos e Familiares
}

\author{
Natalia Schopf Frizzo ${ }^{1}$ \\ ${ }^{1}$ Universidade Federal de Ciências da Saúde de \\ Porto Alegre, RS, Brasil. \\ Anaí Zubik Camargo de Souza ${ }^{2}$ \\ ${ }^{2}$ Pontifícia Universidade Católica, RS, Brasil.
}

\author{
Ana Paula Wernz da Cunha Muller ${ }^{1}$ \\ ${ }^{1}$ Universidade Federal de Ciências da Saúde de \\ Porto Alegre, RS, Brasil. \\ Adriana Mesquita Ozi \\ ${ }^{2}$ Pontifícia Universidade Católica, RS, Brasil.
}

Resumo: O estudo se propôs a compreender as contribuições da atividade musical diante da capacidade de pacientes oncológicos e familiares no enfrentamento da doença, bem como investigar qual o impacto dessa ação nos aspectos biopsicossociais frente ao processo saúdedoença. Trata-se de uma pesquisa descritiva e exploratória, de cunho qualitativo, sendo considerados participantes os pacientes oncológicos em tratamento em uma clínica no Sul do país e seus familiares. A coleta de dados se deu por meio de entrevista semiestruturada. A leitura dos dados foi feita por meio de análise de conteúdo com posterior categorização dos temas emergentes. Percebeu-se que a comunicação estabelecida no grupo por meio das canções representou uma possibilidade de elaboração de conteúdos referentes ao tratamento. Observouse melhora da expressão de sentimentos, ampliação da sensação de apoio, melhora do humor e minimização da percepção dos sintomas atrelados ao tratamento por meio do relaxamento, além do enfoque em memórias saudáveis para além da experiência da doença.

Palavras-chave: Psicologia, Música, Acolhimento, Quimioterapia.

\section{Music as Resource of Coping for Oncology Patients and their Relatives}

\begin{abstract}
This study analyzed the contributions of musical activity in the disease coping capacity of oncology patients and family members, as well as its impact in the biopsychosocial aspects in facing the health-disease process. It is a descriptive, exploratory, qualitative research, with oncology patients being treated in an outpatient clinic in the South region of Brazil, and their family members. A semi-structured interview was used for data collection. Content analysis was conducted by analyzing the data, followed by categorization of the emerging topics. It was noted that the communication established in the group by the songs allowed to work with content related to the treatment. Better expression of feelings, broadening of the feeling of being supported, improved mood, as well as minimization of the perception of symptoms connected to treatment through relaxation were observed, in addition to focusing in healthy remembrances beyond the experience of the disease.
\end{abstract}

Keywords: Psychology, Music, Welcoming, Chemotherapy. 


\title{
Música como Recurso de Enfrentamiento en Pacientes Oncológicos y sus Familiares
}

\begin{abstract}
Resumen: El proyecto se propone comprender los posibles aportes de la actividad musical a la capacidad que tienen los pacientes oncológicos y sus familiares de enfrentar la enfermedad, así como investigar el impacto de dicha acción sobre los aspectos biopsicosociales del proceso salud-enfermedad. Se trata de una investigación descriptiva y exploratoria, de tipo cualitativo; los participantes son los pacientes oncológicos en tratamiento en una clínica en el Sur del Brasil y sus familiares. Se recopilaron los datos mediante entrevistas semiestructuradas. Se analizaron los datos con base en el análisis de contenido y, a continuación, se categorizó los temas emergentes. Se constató que la comunicación establecida en el grupo por medio de las canciones fue una posibilidad de elaboración de contenidos relativos al tratamiento. Se observó una mejora en la expresión de sentimientos, acentuación de la sensación de apoyo, mejora del humor y minimización de la percepción de los síntomas vinculados al tratamiento debido a la relajación, además de que los pacientes se centraron en recuerdos saludables más allá de la experiencia de la enfermedad.
\end{abstract}

Palabras clave: Psicología; Música; Acogida; Quimioterapia.

\section{Introdução}

A música tem acompanhado o homem ao longo de sua história associando-se intimamente a diversas atividades de vida e estando presente em todas as culturas como uma forma de expressão. Sua abrangência atinge os seres humanos de modo integral, em seus aspectos físicos, psicossociais e espirituais. É capaz de exercer caráter social agregador e ainda promover a conexão do sujeito com seu mundo interno por meio da reflexão sobre suas próprias emoções, memórias, ideias e pensamentos (Bruscia, 2016; Ruud, 1998). Assim, pode-se afirmar que a música é uma forma de comunicação universal (Fallavigna, Bellaguarda, Gaio, \& Rosa, 2016).

Para Barcelos (1979), por sua vez, a música é capaz de ir além das palavras. Ela propicia refletir sobre a própria existência e auxilia no enfrentamento de situações de vida. Seu uso terapêutico surge no intuito de suscitar a emergência de conteúdos internos e subjetividades associadas ao medo, aos relacionamentos, à autoestima, à raiva, à culpa, à tristeza e a tantos outros sentimentos, presentes quando a circunstância peculiar de vida é uma enfermidade.

Nesse contexto, devido à capacidade da doença de desestruturar o equilíbrio dos sujeitos, considera-se a música como potencial aliada para o restabelecimento da homeostase. Assim, diversos têm sido os estudos que apontam o recurso musical como importante ferramenta no enfrentamento de doenças, por impactar na estabilização de sintomas considerados recorrentes e facilitar a adaptação a tratamentos, que sensibilizam tanto o doente quanto seus cuidadores (Bergold \& Alvim, 2011; Campos \& Nakasu, 2016; Doro et al., 2015; Klainin-Yobas, \& Yew, 2015; Leão, Puggina, Gatti, Almeida, \& Silva, 2011; Petrovsky, Cacchione, \& George, 2015; Sales, Silva, Pilger, \& Marcon, 2011; Silva, Marcon, \& Sales, 2014).

Por conseguinte, quando a doença em questão traz o simbolismo de ameaça à vida, um severo impacto no indivíduo acontece em sua totalidade. É essa representação que, muitas vezes, o câncer induz às pessoas. Juntamente da notícia do diagnóstico oncológico, subentende-se uma forte mobilização associada principalmente às crenças culturais sobre a enfermidade e ao temor da morte (Karkow et al., 2015). Tal situação faz emergirem sentimentos de perda associados ao adoecimento: mudanças nos papéis desempenhados nos contextos familiar, profissional e social, limitações físicas decorrentes do diagnóstico e do tratamento, comprometimento dos recursos psicológicos de pacientes e familiares (Petersen, 2012). É nesse cenário que a atividade musical ganha destaque como recurso de enfrentamento, facilitando a expressão e a elaboração de momentos difíceis e das subjetividades despertadas ao longo do tratamento.

$\mathrm{Na}$ oncologia, aspectos de relaxamento muscular alterando a percepção da dor, reforço da identidade 
e do autoconceito, alteração do estado de ânimo e manifestação de sentimentos são caminhos possíveis despertados pela música. A vivência de uma atividade musical pode atuar, também, como elo entre diferenças culturais e isolamento, oportunizar participações em grupos e promover entretenimento e diversão nos ambientes em que tratamentos são ofertados (Lafauria et al., 2009; Munroe \& Mount, 1978; Silva et al., 2014). A musicalidade nesses espaços ainda atua como um veículo facilitador da expressão da fé, propiciando conforto espiritual por auxiliar na expressão de dúvidas e questões relacionadas ao significado da vida e de sua finitude (Leão, 2007; Silva et al., 2014).

Este estudo parte, então, do pressuposto de que o adoecimento por câncer acomete uma pessoa impondo impactos que vão além do corpo físico (objetivo), mas que implicam na peculiaridade psíquica individual e coletiva (subjetivo), de forma que o caminho de acesso para o equilíbrio no adoecer passa pelo discurso. É nesse impasse que a psicologia se alia à musicalidade, como uma proposta de intercâmbio dialético clínico por meio da inclusão da música associada à psicodinâmica da palavra (Doro et al., 2015). Então, buscando minimizar o desgaste subjetivo que o câncer traz, com todas as suas ameaças frente à continuidade da vida, o psicólogo assume um posicionamento de mediador nas inter-relações entre o cuidado (enfermo) e o cuidador (família). E lhe é conferida, durante as atividades musicais, as funções de facilitador e restaurador dos conteúdos psíquicos (Zanetti, 2008).

Diante, assim, do exposto, buscou-se com esta pesquisa compreender as contribuições da atividade musical frente à capacidade de enfrentamento da doença por parte de pacientes oncológicos e familiares, bem como investigar qual o impacto dessa ação nos aspectos biopsicossociais frente ao processo saúde-doença. E entende-se relevante ressaltar que são poucos os estudos realizados sobre música em ambientes oncológicos exclusivamente ambulatoriais, o que somou relevância ao estudo desse tema.

\section{Materiais e métodos}

Trata-se de uma pesquisa descritiva e exploratória, de cunho qualitativo. Buscou-se apresentar uma análise do conteúdo subjetivo da experiência de cada indivíduo (Turato, 2003).

Para a coleta de dados, foram utilizadas entrevistas semiestruturadas, guiadas por meio de eixos norteadores (Turato, 2003). As mesmas foram efetuadas após a participação dos sujeitos na atividade musical desenvolvida no ambulatório de quimioterapia de uma clínica no Sul do país. Tal atividade delineou-se em dois encontros semanais, ao longo de três meses, coordenada pela psicologia na presença de uma musicista que conduzia canções em voz e violão. Músicas foram pré-selecionadas e desempenhadas, bem como se disponibilizou espaço livre para escolha de canções pelos próprios participantes.

Os eixos norteadores das entrevistas foram: a notícia do diagnóstico; as primeiras vivências com o tratamento quimioterápico em ambulatório; o impacto da música como terapia durante o tratamento; sentimentos despertados pela música durante a aplicação de quimioterapia; implicações da experiência com a atividade musical na vida diária durante o período de tratamento.

Foram incluídos neste estudo pacientes e acompanhantes maiores de 18 anos. Quanto aos pacientes, independentemente do tipo de neoplasia, participaram aqueles que se encontravam realizando quimioterapia e possuíam Eastern Cooperative Oncology Group (ECOG) entre 0 e 2. Por sua vez, as neoplasias contempladas na amostra foram: mama, ovário, bexiga, cólon, esôfago, pulmão e amígdala.

As entrevistas foram realizadas individualmente com cada sujeito da pesquisa, sendo as mesmas gravadas e, posteriormente, transcritas e analisadas. Para manter o anonimato dos sujeitos, os nomes foram substituídos por um código - Paciente (número) e Familiar (número). A amostra compôs-se de oito pacientes (dois homens e seis mulheres) e sete familiares (três homens e quatro mulheres). As idades situavam-se entre 49 e 78 anos, e o tipo de parentesco dos familiares era de marido, esposa e irmã.

O número de entrevistas foi determinado pela saturação da amostra (Minayo, 2008), a qual foi alcançada após a realização de quinze entrevistas, incorporadas em um processo contínuo de análise de dados iniciado juntamente com o processo de coleta. Após a realização das entrevistas, os dados foram examinados por meio de análise de conteúdo (Bardin, 2010; Turato, 2003). Posteriormente à transcrição do material, foi realizada a leitura flutuante até a impregnação do conteúdo. Tanto por repetição quanto por sua carga emocional, as falas propiciaram a categorização a partir de temas emergentes identificados (Turato, 2003).

Saliente-se que, em todas as etapas da pesquisa, foram considerados os aspectos éticos. Os sujeitos da 
pesquisa receberam esclarecimentos sobre o estudo e suas implicações, de forma que, antes da realização das entrevistas, se submeteram ao Termo de Consentimento Livre e Esclarecido, o qual autorizou sua participação na pesquisa. $\mathrm{O}$ projeto da pesquisa foi aprovado pelo Comitê de Ética CAAE: 60943516.7.0000.5330

\section{Resultados e discussão}

A partir da análise das entrevistas, questões emergiram como categorias relevantes. Em torno dessas temáticas, serão desenvolvidas algumas considerações a seguir.

\section{Paciente, diagnóstico e quimioterapia: "Quero lhe contar de tudo que aconteceu comigo"}

O momento da revelação do diagnóstico de câncer pode ser de grande impacto para o sujeito acometido pelo adoecimento. Petersen (2012) explica, de maneira objetiva, que, por ser uma enfermidade de cunho ameaçador à vida num amplo aspecto, a doença oncológica acaba ocasionando sentimentos de perda. Assim, ele sugere o depoimento da paciente, ilustrando a explicação do autor:

Foi um baque, né, foi um balde de água fria, me senti impotente, me senti assim, perdida total. Peguei o diagnóstico e dirigi, eu chorava na rua. Assim, eu me senti já com o diagnóstico final da morte, me senti assim muito ruim, muito mal mesmo (Paciente 2).

Segundo Costa, Finco, Souza, Medeiros e Melo (2016), a palavra câncer trouxe historicamente um sentido sociocultural de uma doença que remete a uma sentença de morte. Ainda que os avanços tecnológicos tenham contribuído para melhores tratamentos e diminuição da taxa de mortalidade, pode-se observar que o estigma de ser uma doença dolorosa e que mata lentamente persevera entre alguns pacientes acometidos por essa enfermidade:

Eu morri naquele dia. Eu quase caí dura, não conseguia nem levantar da cadeira, né? Daí eu fiquei paradona, parada, né? Apavorada, eu vou morrer, é só no que eu pensei, vou morrer (Paciente 8).
Ressalte-se que o adoecer retrata uma ruptura na vida, em planos e perspectivas de futuro (Costa et al., 2016). Tal experiência faz com que os sujeitos precisem buscar formas de enfrentamento para essa nova situação, como menciona a fala:

Não vou te dizer que eu gostei, gostar ninguém gosta, ninguém quer, mas foi uma coisa... Bem, querer eu não queria, mas veio para mim, então eu vou carregar, vou seguir em frente, vou lutar (Paciente 4).

E é frente a essa busca de recursos que a musicalidade, então, aparece, como ferramenta capaz de instrumentalizar os sujeitos em suas batalhas pessoais. É também nesse sentido que os encontros musicais oportunizam o espelhamento de situações de vida, despertando uma sensação de integridade social e evolução cognitiva, ressignificando as emoções e o sentido da vida (Bergold \& Alvim, 2011).

Assim, o espaço coletivo em que acontece uma atividade musical pode vir a atuar como porto seguro para oportunizar a manifestação das emoções e acolhê-las. Pois se o sofrimento no câncer é multifacetado, o papel do profissional de saúde, principalmente do psicólogo, nesse contexto é facilitar, também com variados recursos - como a música, pelo acolhimento da melodia, por meio das letras das canções - a situação do enfermo, para que ele possa, como diz a composição, "contar de tudo que aconteceu comigo". Assim, um caminho que permita ao doente compreender o impacto do diagnóstico e os modos possíveis de enfrentamento da doença pode se estabelecer. E pode-se almejar, por meio da mediação nas inter-relações (Zanetti, 2008), que o reestabelecimento de saúde mental aconteça conjuntamente ao tratamento físico vivenciado, alcançando resultados biopsicossociais.

Por sua vez, conjuntamente ao processo de elaboração/aceitação do diagnóstico oncológico, o tratamento quimioterápico destaca-se como potencial desafio cotidiano. A pessoa que convive com a enfermidade vive simbólica e corporalmente processos complexos considerados diante do fenômeno de saúde e doença (Costa et al., 2016).

Tal complexidade, da qual fala a autora, se vê nos depoimentos a seguir, que manifestam os impactos corporais, os sintomas e as adaptações à doença, $\mathrm{e}$ 
também a busca por compreensão da própria enfermidade frente aos efeitos de uma quimioterapia:

Ah, é uma coisa que a gente sabe que entra no corpo, parece uma onda, sabe, que leva tudo, leva tudo embora. Sabe aquelas ondas que olha, o primeiro ciclo eu achei que teve muitas reações adversas assim... (Paciente 7).

No fundo foi até bom, que eu vim sem saber... . Mas foi muito bom ter vindo sem saber nada, porque as pessoas falam muito, estragam muito a gente, isso até, às vezes, foi bom ter vindo sem saber nada, porque varia [os efeitos colaterais] de pessoa para pessoa (Paciente 8).

Assim, a quimioterapia aparece circundada por sentimentos múltiplos que podem paralisar o sujeito, como é o caso do medo, se ocorrer de este se tornar uma barreira para a aceitação do adoecimento. E a atenção aos anseios precisa ser ofertada porque estes podem estender-se para complicações no tratamento quando atrelados à descrença quanto à possibilidade de cura (Conde, Lemos, Pozati, \& Ferreira, 2016), como se pode ver neste depoimento: "a gente olhava para a quimio como se fosse... 'ah, está passando por isso e não vai adiantar nada'” (Paciente 6).

Entende-se, assim, frente a uma terapêutica historicamente assustadora e impactante como a quimioterapia, e diante da ruptura que a doença grave produz na vida do sujeito, que este necessita buscar modos de ressignificar a experiência e enfrentar as variadas adaptações necessárias a esse novo momento experienciado (Costa et al., 2016) .

Nesse contexto, a psicologia assume importante papel de mediar o real (tratamento) e o simbólico (expectativas sobre o tratamento), contribuindo para o entendimento psicoemocional do paciente (Doro et al., 2015). Por meio da música, um novo recurso se apresenta, inspirando novas formas de cuidado aos dias dos doentes, imprimindo-lhes a sensação de suporte e ofertando novos sentidos a seu existir no mundo com o câncer. A música pode, então, subsidiar o compartilhamento de experiências, expectativas e estratégias para lidar com o impacto quimioterápico. Ou seja, a atividade musical acaba por intermediar o estar com o outro em sua fatalidade existencial (Silva \& Sales, 2013).

\section{Família, diagnóstico e quimioterapia: "E quando vejo o mar, existe algo que diz que a vida continua e se entregar é uma bobagem"}

Quando se recebe um diagnóstico oncológico, não só o paciente, mas sua rede de relações também sofre impacto (Bergold e Alvim, 2011). Tanto o cônjuge como outras pessoas significativas da família proporcionam importante fonte de apoio social para muitos pacientes de câncer. Quando o doente percebe que essa relação é sólida e apoiadora, seu bem-estar físico e emocional obtém grandes benefícios, pois o relacionamento atua como fonte de amparo, como aponta a fala a seguir:

Na hora de receber o resultado do diagnóstico do médico, ficamos calados, porque a gente esperava uma resposta, e aí a gente se olhou um para o outro, e ele disse assim, vamos em frente, eu quero fazer o tratamento, e foi assim, uma coisa que mostrou que nós dois, a gente ainda tinha muita energia pela frente, que a gente estava lutando para conseguir prolongar essa vida (Familiar 1).

Contudo, Karkow et al. (2015) explicam que alguns familiares reconhecem o estigma do câncer, e isso também implica um abalo pessoal, pois consideram que essa imagem ajuda a aumentar o medo e a preocupação em relação ao que pode vir a acontecer com seu familiar:

Foi um baque, um impacto muito grande assim porque ela é irmã mais velha, ela estava passando por esse problema de saúde. Foi um baque assim, porque tu fica com aquela memória, que câncer te mata logo, né? (Familiar 2).

O impacto foi chocante porque a gente não tinha conhecimento de nada e pegou toda a família de surpresa, quando deu que era positivo nos derrubou, né?! (Familiar 3).

Desse modo, ao mesmo tempo em que o apoio da família é um dos principais recursos externos utilizados pelo paciente para o enfrentamento da doença, os familiares também sofrem ao lidar com as necessidades emocionais do integrante adoecido. E vale ressaltar que, muitas vezes, o câncer é percebido como uma doença ameaçadora à vida, daí o temor que ele acarreta (Karkow et al., 2015), como se observa: 
No primeiro momento, não queria falar do assunto, né, eu fugia do assunto, eu que às vezes fico aborrecido com a possibilidade de ficar sozinho (Familiar 4).

Olha, no primeiro momento eu senti o fim da vida, que é uma doença que todos têm medo de falar (Familiar 7).

Apreende-se, então, que o sofrimento pela condição de saúde do ente querido pode encontrar abrigo nas atividades musicais pela oferta de uma escuta pautada na visão transdisciplinar de cuidados de saúde (musicistas, psicólogos, equipe assistencial). O intercâmbio entre a música, suas letras e a atenção dos profissionais ali presentes oportuniza compreender o relacionamento interpessoal, a expressividade emocional e afetiva e os aspectos histórico-culturais dos indivíduos e grupos que ali passam a conviver (Ruud, 1998).

Também vale acrescentar que, diante da impossibilidade de alterar a situação do diagnóstico, cabe aos familiares lidar com sua angústia e com a própria fragilidade, validando a necessidade de apoio para o enfrentamento de sua condição existencial. Isso se dá porque o câncer desperta sentimentos de vulnerabilidade, receio, insegurança e incerteza (Silva et al., 2014). O que é possível perceber no relato:

Daí a gente se perguntou e agora? Quem vai dizer para ele, como eu vou dizer para ele? Não posso, né, eu disse, não, vou marcar consulta amanhã com o médico dele lá de Osório, né, que daí ele vai falar, né. Daí quando ele falou eu dei uma baqueada assim feia (Familiar 5).

É nesse contexto que se entende a relevância da partilha grupal mediada pela musicalidade, pois ela pode atuar como recurso de acolhimento e é capaz de favorecer o estabelecimento de relações e vínculos voltados a uma concepção humanizada do cuidado. As emoções evocadas pela doença e a tentativa de ressignificar a experiência podem encontrar nas letras das canções uma espécie de consolo. E o espelhamento produzido no coletivo, que compartilha vivências similares diante da enfermidade, permite que a música atue como elo entre subjetividades, reduza a sensação de despersonalização, aumente a autoestima e proporcione conforto e bem-estar. Ressalte-se também que, nesse processo, a participação dos sujeitos na escolha musical permite estimular sua autonomização (Bergold \& Alvim, 2009).

Contudo, não só pelo impacto do diagnóstico sofrem as famílias. Seus anseios muitas vezes também se estendem ao possível impacto do tratamento antineoplásico (Silva et al., 2014), como aponta a fala: " $a$ gente chegou meia assustada, eu confesso, eu já tinha convivido muito com quimioterapia por causa da minha irmã, que eu acompanhava ela em tudo, mas mesmo assim fiquei meia assustada" (Familiar 5).

Existem ainda dificuldades da família em lidar com os efeitos colaterais e com as crenças negativas sobre a quimioterapia. De acordo com Farinhas, Wendling e Dellazzana-Zanon (2013), problemas de ordem emocional que ocorrem com frequência em pacientes com câncer também acometem seus familiares:

Essa quimioterapia parecia um deus nos acuda, porque a gente não sabia a profundidade dessa doença e desse tratamento (Familiar 7).

Ela não aceita muito ter perdido o cabelo, essas coisas assim, agora que ela está de peruca, com outro astral, né, mas o início foi difícil, então eu fiquei abalada com ela por esse início (Familiar 2).

Quando a "Paciente 6" chegou a ficar totalmente sem cabelo, que foi a primeira fase das sessões, os irmãos homens ficaram mais transtornados (Familiar 6).

Compreende-se, assim, o quanto a família angustia-se e identifica sua própria fragilidade, evidenciando a necessidade de amparo para encarar a atual situação (Silva et al., 2014). A musicalidade, nesse contexto, aponta como válvula de escape dessas emoções. As lembranças das primeiras vivências do tratamento, marcadas por receios e dúvidas, cedem espaço ao entretenimento, conduzindo a momentos de emoção compartilhada. Como recurso de comunicação, a música consegue promover relação interpessoal e abertura para o discurso, viabilizando o atendimento das necessidades emergentes.

Vale ressaltar ainda que, frente às memórias evocadas pelas experiências iniciais com a quimioterapia, a ação reflexiva da música permite promover a receptividade, estímulos e relaxamentos, explorando ideias e pensamentos. E isso, como aponta Bruscia (2016), 
acaba por facilitar a ressignificação dessas reminiscências e estabelece conexões entre o ouvinte e o grupo, ampliando a capacidade de oferta de suporte dos profissionais. E no caso da psicologia, expande-se a escuta ativa, que é orientada para favorecer melhores adaptações ao tratamento oncológico.

Assim, é no encontro de pluralidades que a prática musical acontece, desempenhando papel comunicador e disparador de sensibilidades e de recursos para encarar o câncer. Por meio da música, torna-se possível identificar e expressar muitas das emoções que a palavra pura não consegue manifestar. A linguagem configura-se, portanto, como uma das maneiras de ser-estar no mundo e também atua como caminho para ver-se absorvido por ela. Desse modo, se diante da doença "a vida continua e se entregar é uma bobagem”, a comunicação estabelecida nos encontros musicais fornece guarida para que os sujeitos expressem suas percepções sobre a canção e sobre o novo papel agora ocupado pela família - cuidadores informais de alguém que se ama (Sales, 2011).

\section{O paciente e o impacto da música no tratamento: "Que a vida devia ser bem melhor e será, mas isso não impede que eu repita: É bonita, é bonita e é bonita!"}

Oliveira, Oselame, Neves e Oliveira (2014) enfatizam que, dentre as terapias integrativas mais usadas, a música destaca-se como recurso terapêutico complementar a um tratamento quimioterápico, promovendo alterações físicas, mentais e sociais. Ela pode ser utilizada pela equipe de saúde com o intuito de oferecer um tratamento mais humanizado, melhor interação entre a equipe e o paciente e entre a própria equipe multidisciplinar da saúde.

Pode servir ainda como intervenção complementar para o alívio da dor e de outros sintomas, como a angústia espiritual, distúrbios do sono, desesperança, risco para solidão, isolamento social e estresse (Gonçalez, Nogueira, \& Puggina, 2008), auxiliando a recuperação da saúde mental e a adaptação ao tratamento de uma enfermidade, como se pode observar nas falas a seguir:

Escutando a música é outra coisa, desvirtua o cérebro, não pensa em nada, pensa na música, não pensa em doença, tratamento, passa o tempo a música, né (Paciente 5).
As pessoas ali hoje eu acho que estavam brincando, fazendo tricô, porque eu achei que elas, graças a deus, não tinham nada. Eu acho que a música espairece e tu se esquece do problema que tu tem, entendeu? Então a música ajuda a espairecer e a gente a não imaginar o que está entrando pelo corpo da gente (Paciente 8).

O excerto a seguir, em consonância, ilustra o que Petersen (2012) destaca ao afirmar que a música entra como uma ação terapêutica que pode trazer também a reflexão sobre os aspectos emocionais, desencadeando questionamentos sobre o sentido e o cuidado com a vida durante o tratamento:

Ah, é muito bom, é ótimo, é excelente porque trata de alma, escutar a música é vivenciar a vida, faz com que a gente pense, retroceda ao passado $e$ traga ele para o presente e pense na gente mesmo, em si mesmo, . . . parar e pensar na letra, e isso com certeza motiva a gente a se cuidar, começando pela alma, que eu digo que escutar música faz bem para a alma, para a nossa saúde mental e isso é maravilhoso. (Paciente 3)

Em relação aos efeitos psicológicos da música, Bréscia (2009) expõe que a mesma pode servir como uma espécie de elo, com suas experiências significativas do passado, particularmente no que diz respeito a melodias que evocam memórias específicas:

Para mim, hoje ter participado desse momento foi maravilhoso, foi como ver a criança que tinha em mim, passou um filme em minha cabeça através da música, isso faz bem para a gente parar para pensar, escutar a música, escutar a letra da música. Foi maravilhoso, isso faz muito bem, é saúde. (Paciente 3).

A música te reporta para umas coisas gostosas, de infância, de memória, coisas boas que você viveu, vive, né, então é uma terapêutica, eu sinto como uma terapêutica, ela está fazendo a integração da minha quimio, eu acho que a música é uma coisa indescritivel, eu acho que você fecha os olhos e se reporta, você viaja, é muito gostoso, é muito bom (Paciente 2).

Muita lembrança, né, coisas assim mais antigas, eu gosto, não sei que nome dar, mas eu acho que é lembrança, né, o passado vem aflorando assim, né. Aquela coisa assim que a gente gosta muito (Paciente 6). 
A música promove, assim, melhorias no estado anímico do paciente, estimula funções cognitivas, ativando memórias para fatos e eventos, favorece o desenvolvimento da comunicação (verbal e corporal), facilitando uma melhor adaptação ao tratamento (Bréscia, 2009). Daí a importância de oferecê-la como uma atividade complementar enquanto o tratamento quimioterápico acontece.

Nessa perspectiva, Fallavigna et al. (2016) explicam que a música ocupa o lugar da emoção e possibilita a travessia entre o emocional e o racional, mobilizando conteúdos com os quais a comunicação verbal muitas vezes não é suficiente para lidar. Ela favorece a transcendência de sentimentos que poderiam atuar como angustiantes, cedendo espaço para o bem-estar:

Ah, eu acho assim que a música te dá uma paz, uma leveza, tu fica leve, dia de quimio para mim, eu venho feliz da vida, porque assim, tem a música, sinceramente eu venho para cá e o dia da quimio é o dia bom da semana, eu esqueço que eu tenho casa, eu esqueço tudo, eu gosto muito de estar aqui, porque assim, ó, eu fui acolhida por vocês (Paciente 4).

Se vir [a música] é melhor, claro, a gente passa o tempo mais rápido, né, eu fico contente também, né, pelo menos me ajuda a passar o tempo (Paciente 1).

Vale destacar igualmente que a música, atrelada ao contexto cultural, muitas vezes tem a capacidade de relacionar-se a momentos significativos da biografia dos sujeitos, mostrando o quanto "a vida é bonita" (Bergold \& Alvim, 2011). Desse modo, durante o tratamento, é possível que se resgatem momentos de saúde em meio à doença, pois ao cuidar das emoções, o corpo físico pode relaxar, e os silenciamentos singulares ganham palco em meio às trocas que a convivência social/grupal promove durante a atividade musical. Aqui, o impacto biopsicossocial da música aparece, e a musicalidade conquista aliados por um melhor fazer/cuidar na oncologia.

\section{Impacto da música no tratamento segundo a família: "A minha gente sofrida despediu-se da dor pra ver a banda passar cantando coisas de amor"}

Silva et al. (2014) assinalam que, diante da necessidade de falar e ser ouvido, a palavra do outro pode significar para o ser-no-mundo uma possibilidade de cuidado, haja vista que, por meio da palavra, os seres expressam sua existencialidade e acolhem a coragem, o consolo e o ânimo necessários para viver e conviver com o câncer. Nesse cenário, a parceria interdisciplinar entre a psicologia e a música torna possível alargar o campo de ação na direção da acessibilidade ao potencial intrínseco de cada um (Doro et al., 2015), despertando sensações, sentimentos e desenvolvendo habilidades comunicativas:

Eu gosto da música, me dá uma sensação boa, porque dai eu já falo, eu gosto dessa música por causa disso, daquilo, são coisas que no dia a dia a gente não fala. Todo mundo: "Ah, eu gosto daquela música que me lembra de tal coisa, né?". E aqui a gente fala, né, é bem incrível (Familiar 5).

A comunicação que se desenvolve, pois, entre familiares reflete a comunhão ofertada pela atividade musical ao longo do tratamento. Os grupos ali formados pelo encontro com a música em ambulatório de quimioterapia oportunizam o compartilhar de experiências com outros seres que vivenciam facticidades semelhantes, pois é estabelecido um ambiente reflexivo e interativo mediado pela dialogicidade e pela escuta sensível (Silva et al., 2014), como se observa na fala: "a gente está ali conversando outras coisas, mas aí com a música, já surgiu outro tema ali. Tu vê que a dona já falou, a outra já falou, então a experiência de um é válida para o outro, sabe?" (Familiar 5).

Nesse sentido, percebe-se que outro ponto de amparo surge com a grupalidade mediada pela música: o suporte psicoemocional que o paciente vivencia durante a atividade musical pode auxiliar diretamente o familiar no enfrentamento da doença. Isso se dá pelo fato de a musicalidade ser capaz de transformar desconforto em conforto, mesmo que por poucos momentos, trazendo valor significativo para ajudar os familiares a cuidarem do ente fragilizado pelo câncer. Assim, conforme aponta Fallavigna et al. (2016,), "a música como terapia tem o poder de preencher a alma do ser humano" (p. 9):

Olha, eu não digo que eles não sofram pela doença, mas isso aí transmite para eles uma tranquilidade, dá um outro ritmo na vida. Essa terapia aí que vocês estão fazendo eu acho excelente (Familiar 6). 
É, eu, por exemplo, sempre fui da ideia que tudo é válido na vida, e a "Paciente 6", por exemplo, ela adora esse momento, ela fica triste quando se desencaixa da música, porque quando ela chega em casa, ela não me diz se passou bem ou passou mal, mas diz se hoje não teve música! (Familiar 4).

Seja, então, pela ameaça à vida que o câncer traz, seja pela intensidade do tratamento quimioterápico, $\mathrm{o}$ ato de cuidar, nas condições de um adoecimento oncológico, acaba por exigir muita dedicação. A sobrecarga física e emocional, relacionada ao tempo despendido nesse cuidado e às dificuldades inerentes, soma pontos para que as famílias também precisem ser cuidadas. Então, se a música tem a capacidade de tornar os sujeitos mais comunicativos, ela acaba tornando-se um suporte psicossocial e espiritual, pois desperta força e coragem para que eles transcendam a angústia da realidade presente e retomem a esperança. $\mathrm{O}$ encontro musical constitui-se, assim, em um espaço concreto para que profissionais se sensibilizem com a condição desses pacientes e seus familiares e desenvolvam uma escuta sensível e uma assistência qualificada para que a família tenha condição de cuidar mais e melhor daqueles que amam (Sales et al., 2011).

\section{O paciente, a música e os sentimentos: "Cada um de nós compõe a sua história, cada ser em si carrega o dom de ser capaz, de ser feliz"}

A música como atividade terapêutica em um ambiente de saúde tem a capacidade de despertar variados sentimentos, os quais Silva et al. (2014) enfatizam como a condição de tocar e ser tocado, podendo, assim, compartilhar emoções e, particularmente, experimentar manifestações de alegria ou tristeza. A isso alude a fala do paciente 2: "desperta amor, desperta paixão, desperta carinho, muito carinho, uma coisa assim que tu te sente acolhida, é como se tivessem te fazendo um carinho".

A música como terapia também torna o paciente mais comunicável; representa uma ferramenta de apoio que desperta coragem para transcender a angústia de sua condição existencial. Além disso, ela atua como entretenimento, traz alegria e emoção, mesmo que por poucos momentos, minimizando aquela aflição relacionada, em casos mais graves, à ameaça de terminalidade da vida (Fallavigna et al., 2016). Como é possível verificar nos relatos:
Alegria, fico alegre, fico faceiro, não pensa em doença, não pensa em nada quando está escutando música, não pensa, né, quando está escutando, desvirtua, tira o pensamento da doença (Paciente 5).

Fica assim, ó: ah, que pena que terminou, eu queria mais, eu queria todos os dias (Paciente 4).

Outro aspecto importante desse processo é pertinente à espiritualidade, pois segundo Costa et al. (2016), a mesma também é bastante utilizada por pacientes com câncer que referem orar e fazer promessas como maneiras de expressar sua fé, na tentativa de melhor se ajustar à situação de doença.A influência da música nesse aspecto espiritual pode ser vista no relato que segue:

$\grave{A}$ noite, antes de dormir, eu sempre rezo, faço evangelho em casa, eu rezo, as pessoas que estão passando por aquilo [...] e deito na cama e rezo de novo e lembro da música, das pessoas que estavam aqui, e agradeço todas as noites esse lugar aqui [a clínica] (Paciente 8).

Silva et al. (2014) assinalam que o paciente, diante das preocupações e incertezas de sua vida, reaviva reminiscências. Dessa forma, os encontros musicais podem atuar como um remédio para a dor e o sofrimento e como um alimento espiritual, como apontam os discursos:

Eu ouço essas meditações à noite, isso me ajuda muito a pegar no sono, a acordar no outro dia melhor, essas [músicas] aqui também, me despertou muita paz, muita tranquilidade, muita alegria, eu adoro vir nos dias que ela está aí, para eu poder ouvir (Paciente 7).

Ela está tocando... aquilo fica, te soa bem nos ouvidos, te dá uma paz, eu sinto assim da música, eu acho esse projeto da música, acho que tem beneficios para as pessoas, não viu que a senhora ali disse que a música cura até a dor dela?! (Paciente 4).

Assim, os encontros musicais acabam por permitir a expressão de sentimentos, estimular a abertura ao mundo e a si mesmo, oferecendo um momento de reflexão existencial e espiritual e impulsionando um 
melhor ajuste ao momento do tratamento. Na perspectiva de vencer a luta contra o câncer, a musicalidade guiada no ambulatório quimioterápico acaba, então, por constituir um caminho para melhorar a qualidade de vida (Ferreira, Dupas, Costa, \& Sanchez, 2010), representando um suporte que proporciona conforto, reflexão e motivação diante das adversidades que vêm do enfrentamento da doença (Sales et al., 2011).

\section{A família, a música e os sentimentos: "Veja a nossa vida como está, mas eu sei que um dia a gente aprende... quem acredita sempre alcança..."}

A música costuma apresentar-se como instrumento facilitador de grande valia na comunicação entre paciente e família. Isso se dá por existirem casos em que os sujeitos sentem-se limitados a expressar-se por meio das próprias palavras, em decorrência das morbidades inerentes da doença e do tratamento. Uma vez que o exprimir encontre-se, então, reduzido, a integração da comunicação pode ser articulada com alguns recursos provenientes de metáforas, analogias, parábolas, filmes, parcerias com outras especialidades e arte, por sua contribuição terapêutica como ação facilitadora na manifestação dos componentes subliminares da psique (Doro et al., 2015). A isso servem os encontros musicais, que, conforme Fallavigna et al. (2016), funcionam como suporte para lidar com a doença de um ente querido, influenciando positivamente no curso da doença por meio do aprendizado no compartilhar das emoções:

É um sentimento de prazer, porque tu está ali escutando e já está pensando em como a gente vive, essa música diz tudo, essa letra que está cantando é a letra que a gente precisaria para seguir a vida para frente, né? (Familiar 1).

Eu fiquei maravilhada com esse projeto de vocês, muito bom, olha, que vocês continuem com esse projeto, para esse povo que vem aqui com o problema que tem na vida deles, isso aí eu acho que é o melhor momento que eles vivem, que eles saiam daquele problema que eles têm, que eles saiam do mundo, que eles vejam de outra forma (Familiar 6).

Por conseguinte, cabe também acrescentar que, como forma de comunicação, a música produz sentimentos variados que propiciam refletir sobre a própria existência e auxiliam na administração de situações vividas (Barcelos, 1979). Isso pode trazer conforto e amparo a quem ouve, induzir o indivíduo à percepção de si em sua singularidade, aspecto muito relevante quando se fala no cuidado ao cuidador, conforme se vê nas sequências:

Eu acho que o que eu entendi ali despertou, assim, que a gente tem que aproveitar a vida, o momento, que a gente não sabe o dia de amanhã (Familiar 3).

Eu me abro muito, eu conto coisas para elas, para vocês aqui que eu não falo para ninguém, né, e eu falo na frente de todo mundo, porque, às vezes, eu estou ali na música e eu falo para todo mundo, e eu estou assim mais solta (Familiar 5).

[A música] me passa muito aquela coisa assim do conforto, da lembrança... ela começou a falar da mãe dela e eu me lembrei da mãe, que a mãe também estaria assim do lado, e eu sei que ela está, pelas nossas convicções religiosas, esse tipo de coisa boa assim, sempre com aquela coisa de tu trazer sentimentos bons (Familiar 2).

É possível verificar, pois, o quanto, mesmo diante do sofrimento e da desesperança, o equilíbrio pessoal aparece com a música, produzido em meio a uma harmonia expressa pela consciência de emoções profundas e de descarga emocional (Fallavigna et al., 2016). Desse modo, também vale considerar que a possibilidade de construir novos significados para o adoecer e para os receios de conviver com um ente querido é transpassada aos familiares, assim como para os pacientes é relevante o amparo espiritual, entendido como aporte a crenças e valores que constituem o existir. Nesse sentido, a possibilidade de trazer novos sentidos à experiência do câncer e do papel enquanto cuidador de um familiar vincula-se à habilidade dos profissionais de propor ações que amparem tais demandas. A atividade musical vem, assim, ao encontro desse cuidado espiritual e humanizado por permitir ao familiar ouvir atentamente o doente, acalentá-lo, estar presente em sua dor e sofrimento (Pinto et al., 2015).

\section{Reflexos da música em longo prazo: "Marcas do que se foi, sonhos que vamos ter, como todo dia nasce, novo em cada amanhecer"}

Quando se reflete sobre o impacto da música na vida daqueles que com ela interagem, passamos a entendê-la como uma ação mobilizadora de afetos. 
Isso se complementa pela capacidade da música de exercer ação psicofisiológica, favorecendo o indivíduo, por meio de seus elementos constitutivos (ritmo), elementos ativos (melodia), elemento afetivo (harmonia), elemento intelectual (letras), podendo auxiliar, assim, os sujeitos que com ela interatuam. Como ferramenta terapêutica em ambientes de saúde/tratamento, percebe-se que a música age, ainda, tanto no auxílio da situação presente (adoecimento) quanto no enfrentamento das relações e adaptações que a doença exige dos envolvidos (para além do curto prazo). E pode-se ilustrar essa ação com a fala a seguir:

É um momento de relaxamento mental, tu para e escuta e interioriza e daqui vai para a mente, né, e a gente pode chegar em casa e compartilhar, falar, chegar contando a experiência de hoje que foi maravilhosa de ouvir música no ambulatório. É uma bênção poder escutar a música, parar para ouvi-la, para depois chegar em casa, comentar com o pessoal o quanto faz bem para a saúde da gente, com certeza (Paciente 3 ).

Considera-se também que o recurso musical busca proporcionar expressão ao cuidador, seja em forma de palavras, seja de sons ou mesmo de silêncios, podendo auxiliá-lo na melhoria da qualidade de vida dele e de seus entes "cuidados", contribuindo para que essa relação/vinculação seja mais saudável, gerando frutos para a vida diária, transpondo o ambiente de tratamento (Santos, Zanini, \& Esperidião, 2015):

Pode trazer bastante beneficio, né, porque aí a gente pode parar um pouquinho e vou raciocinar: aquela música estava falando sobre esse assunto, ou tu quer relaxar, vai escutar uma música, vou procurar aquela música que estava tocando lá [no ambulatório de quimioterapia], eu acho que muda a nossa rotina (Familiar 3).

Depois de ouvir uma música na voz dessa menina, que ela é excelente, a pessoa tem que sair melhor [daqui] (Familiar 4).

Por conseguinte, Karkow et al. (2015) esclarecem que, frente às incertezas advindas da situação de saúde do paciente, inclusive no que diz respeito à possibilidade de sua morte, a família busca, em suas crenças, elementos que a mobilizem esperançosamente. Ainda vale salientar que a reestruturação dos papéis familiares aparece diante de uma enfermidade e faz com que os entes encontrem, em atividades como a música, ajuda para identificar recursos que impulsionem sentimentos de confiança, otimismo, capacidade de superação e serenidade:

Eu acho que esse momento que eles vivem aqui, dentro dessa clínica, esse pequeno ato, esse pequeno gesto que vocês fazem aqui, eu acho que eles vivem o mundo de sonhos (Familiar 6).

A gente vai tranquilo no caminho, não vê risco de nada, até chegar em casa, que o nosso caminho não é muito perto, dá uns 25 quilômetros, $e$ nesses 25 quilômetros, a gente ainda tem, parece, a pessoa tocando no ouvido da gente. Serenando e a gente vai com calma, vai indo com calma até chegar ao nosso destino (Familiar 7).

Pode-se, então, pensar que a atividade musical medeia, assim, a conversação e a emersão de um estado de isolamento e, muitas vezes, de sofrimento, seja pela tranquilidade que pode produzir, seja por algumas mudanças que é capaz de acarretar nos sujeitos, despertando novos modos de olhar para a vida e de viver a vida (Silva et al., 2014), como se pode observar:

É como se uma mãe tivesse acarinhando um filho, uma mãe canta para um filho ninar, um carinho, um afago. Aquela música que ela canta é carinho para mim. Vou sair daqui leve, com o soar da música ainda em meus ouvidos, tá? É muito bom (Paciente 2).

Tềm problemas, muita gente com problema, $e$ muitas vezes eles não dividem com ninguém, não tem com quem dividir, e aquilo ali eles assumem para si. E aqui dentro da clínica, um momento de tranquilidade, um momento de sonho, eles tentam pensar neles. Ameniza, ameniza, com certeza, pela minha irmã eu vejo. Olha o que a "Paciente 6" é agora, "Paciente 6" não foi no passado! (Familiar 6).

Compreende-se, assim, que a música facilita a expressão de emoções, a comunicação interpessoal, a interação entre os indivíduos e a equipe de saúde e oportuniza o compartilhamento de experiências, tornando a vivência do adoecer mais leve de ser enfrentada: 
Eu assim, ó, eu acho que me tornei uma pessoa bem mais alegre e mais comunicativa. Eu me surpreendo, aqui eu converso muito, eu rio, eu brinco com as gurias, mas eu não sou geralmente assim, eu sou mais tímida, só que soltei mais, eu consigo conversar mais, eu consigo falar da doença dele sem ficar com aquela angústia (Familiar 5).

Tu já sai com outro sentimento daqui, né? Ela fez o tratamento, mas com certeza, ela vai sair, eu vou sair mais confortável, tu sai assim meio leve. Esse momento eu acho que foi muito bom, me tirou muito o peso do que eu estava passando nos últimos dias, eu acho que te relaxa, te dá conforto, alivia o estresse. Foi esse momento de me deixar relaxada, massageada, vou dizer assim que eu estava precisando, me senti como se tivesse feito ali uma massagem nas costas [risos], me tirasse um peso, por isso acho que é bom, bom continuar (Familiar 2).

Vê-se, desse modo, a relevância de reconhecer que um corpo não é um mero corpo, mas a morada de um indivíduo singular, emotivo e possuidor de uma identidade genética e energética expressa na peculiaridade psíquica (Doro et al., 2015). É nesse aspecto que a musicalidade se entrelaça como técnica terapêutica complementar, pois, ao proporcionar relaxamento, contribui para que o sujeito modifique suas relações com seu corpo, com outras pessoas e com suas próprias emoções. Constrói-se, com isso, oportunidades de reorganizar e reintegrar o que é percebido como desestruturado (Souza, Forgione, \& Alves, 2000), principalmente quando a experiência do momento é uma doença grave como o câncer.

Nesse entrelaço biopsicossocial, a música tem, assim, alcançado efeitos psicofisiológicos que podem contribuir para a redução do estresse e dos níveis de cortisol (Nuki, Yoshiuchi, \& Nomura, 1999) e permitir elaborar uma intrincada rede de sensações, emoções, sentimentos e significados simbólicos e culturais, intrínseca a cada ser humano, capaz de ressoar e produzir diversos efeitos terapêuticos. Como se pode observar nos relatos, a música proporciona, aos cuidadores e/ou familiares, um recurso adicional, pois contribui para a humanização dos espaços de tratamento, podendo criar momentos de prazer, melhorar o humor e alcançar relaxamento e bem-estar (Petrovsky et al., 2015). E aos pacientes, seus impactos estendem-se à redução da dor, do estresse, à promoção de conforto, relaxamento muscular e dignidade, podendo, inclusive, alcançar efeito ansiolítico prolongado após a intervenção (Klainin-Yobas, \& Yew, 2015; Leão et al., 2011).

\section{Considerações finais}

Durante um adoecimento grave, como em função de câncer, os sujeitos envolvidos tendem a apresentar implicações em seu bem-estar e qualidade de vida. Seja nos pacientes, seja em seus familiares, as emoções são impactadas desde o diagnóstico. Nesse sentido, a oportunidade de utilizar música como ferramenta terapêutica confirmou os achados da literatura, mostrando-se como de grande potencial, pois o ato de ouvir, cantar, improvisar ajudou a integrar mente, corpo e espírito nas vivências de tratamento compartilhadas no ambulatório de quimioterapia.

Observou-se que não só para o paciente, mas também para o familiar/cuidador, benefícios foram alcançados. O diálogo estabelecido nos encontros por meio das canções representou uma possibilidade de elaboração de conteúdos referentes ao tratamento, abordando aspectos existenciais/espirituais e afetivos, contribuindo também para a socialização. Observou-se melhora da expressão de sentimentos, ampliação da sensação de apoio, melhora do humor, além do enfoque em memórias saudáveis para além da experiência da enfermidade, facilitando o ajustamento psicológico frente à doença. Alcançou-se ainda a minimização da percepção dos sintomas atrelados ao tratamento por meio do relaxamento, impactando positivamente nos aspectos biológicos/orgânicos oriundos do diagnóstico e do tratamento.

Também foi possível observar que a ação proposta ofertou no ambulatório de quimioterapia momentos de restabelecimento da saúde mental por constituir-se em uma ferramenta de humanização dentro da saúde, favorecendo espaços de acolhimento autêntico, conforme ressaltados nas falas dos sujeitos entrevistados. Ao acolher aspectos biopsicossociais e espirituais, o transitar pelo tratamento, bem como o enfrentamento da enfermidade, tornou-se mais equilibrado, por resgatar espaços de saúde em meio à doença.

Por fim, considera-se oportuno refletir que este estudo, em virtude de ser qualitativo, contextualizando no tempo e no espaço as vivências dos sujeitos envolvidos, carece em apresentar dados generalizáveis. Contudo, os resultados podem ser utilizados em 
situações similares, contribuindo para aprofundar o conhecimento e a reflexão acerca da temática. Nesse sentido, destacamos a relevância do desenvolvimento de outras pesquisas nessa linha, posto que a música pode se configurar como uma grande aliada da psicologia, bem como para outras especialidades que considerem o desdobramento terapêutico do cuidado como uma possibilidade de construção e/ou de resgate interativo de atitudes saudáveis, que favoreçam o bem-estar diante de doenças, incluindo as ameaçadoras, como o câncer.

\section{Referências}

Barcelos, L. R. A. (1979). Importância da música na vida cultural e biológica do homem. Inédito. Rio de Janeiro, RJ: Autor.

Bardin, L. (2010). Análise de conteúdo. Lisboa: Edições 70.

Bergold, L. B., \& Alvim, N. A. T. (2009). A música terapêutica como uma tecnologia aplicada ao cuidado e ao ensino de enfermagem. Escola Anna Nery, Revista de Enfermagem, 13(3), 537-542. https://www.scielo.br/pdf/ean/v13n3/ v13n3a12

Bergold, L. B., \& Alvim, N. A. T. (2011). Influência dos encontros musicais no processo terapêutico de sistemas familiares na quimioterapia. Texto \& Contexto - Enfermagem, 20(n. esp), 108-116. https://www.scielo.br/scielo. php?pid=S0104-07072011000500014\&script=sci_arttext\&tlng=pt

Bréscia, V. P. (2009). A música como recurso terapêutico. Anais do Congresso Brasileiro de Psicoterapias Corporais, $X I V$, 1-9. https://www.centroreichiano.com.br/artigos/Anais-2009/BRESCIA-Vera-Pessagno-A-musica.pdf

Bruscia, K. E. (2016). Definindo musicoterapia. Rio de Janeiro, RJ: Enelivros.

Campos, L. F., \& Nakasu, M. V. (2016). Efeitos da utilização da música no ambiente hospitalar: Revisão sistemática. Revista Sonora, 6(11). https://www.publionline.iar.unicamp.br/index.php/sonora/article/view/686/659

Conde, C. R., Lemos, T. M. R., Pozati, M. P. S., \& Ferreira, M. L. S. M. (2016). A repercussão do diagnóstico do câncer de mama no contexto familiar. Revista Brasileira de Pesquisa em Saúde, 18(4), 84-92. http://revista.uninga.br/ index.php/uninga/article/view/1263/885

Costa, J. M., Finco, G. M., Souza, R. L. G., Medeiros, W. C. M., \& Melo, M. C. M. (2016). Repercussões biopsicossociais do diagnóstico de câncer colorretal para pacientes oncológicos. Revista da SBPH, 19(2), 5-23. http:/ /pepsic.bvsalud.org/scielo.php?script=sci_arttext\&pid=S1516-08582016000200002

Doro, M. P., Pelaez, J. M., Dóro, C. A., Antonechen, A. C., Malvezzi, M., Bonfim, C. M. S., \& Funke, V. M. (2015). Psicologia e musicoterapia: Uma parceria no processo psicoativo dos pacientes do Serviço de Transplante de Medula Óssea. Revista da SBPH, 18(1), 105-130. http://pepsic.bvsalud.org/pdf/rsbph/v18n1/v18nla06.pdf

Fallavigna, D., Bellaguarda, M. L. R., Gaio, T. C., \& Rosa, M. C. (2016). A música na assistência à saúde de pacientes em cuidados paliativos. Revista Eletrônica Estácio Saúde, 5(1). 190-201. http://revistaadmmade.estacio.br/index. $\mathrm{php} /$ saudesantacatarina/article/view/2240/1065

Farinhas, G. V., Wendling, M. I., \& Dellazzana-Zanon, L. L. (2013). Impacto psicológico do diagnóstico de câncer na família: Um estudo de caso a partir da percepção do cuidador. Pensando Famílias, 17(2), 1-19. http://pepsic. bvsalud.org/scielo.php?script=sci_arttext\&pid=S1679-494X2013000200009

Ferreira, N. M. L., Dupas, G., Costa, D. B., \& Sanchez K. (2010). Câncer e família: Compreendendo os significados simbólicos. Ciência, Cuidado e Saúde, 9(2), 269-77.

Gonçalez, D. F. C., Nogueira, A. T. O, \& Puggina, A. C. G. (2008). O uso da música na assistência de enfermagem no Brasil: Uma revisão bibliográfica. Cogitare Enfermagem, 13(4), 591-596. https://pdfs.semanticscholar. org/41b4/3bffdf4e6c5618567ca46c29b049cf545c91.pdf

Karkow, M. C., Girardon-Perlini, N. M. O. Stamm, B., Camponogara, S., Terra, M. G., \& Viero, V. (2015). Experiência de famílias frente à revelação do diagnóstico de câncer em um de seus integrantes. REME: Revista Mineira de Enfermagem, 19(3), 741-751. http://reme.org.br/artigo/detalhes/1036

Klainin-Yobas, P., \&Yew, S. (2015). Effects of relaxation interventions on depression and anxiety among older adults: A systematic review. Aging Ment Health, 19(12), 1043-55. https://pubmed.ncbi.nlm.nih.gov/25574576/

Lafauria, M. M., Barbosa, D. R. C., Días, J. M. G., Tamayo, D. M. J., Moreno, L. B., Ramírez, L. P., Ramírez, A. G. S., \& González, J. H. T. (2009). Mujeres en tratamiento de cáncer, acogidas por un Albergue de Apoyo: Circunstancias y perspectivasde cuidadodeEnfermería. RevistaColombianadeEnfermería, 4(4),61-72.https://revistacolombiana deenfermeria.unbosque.edu.co/article/view/1414/1020 
Leão, E. R. (2007). Reflexões sobre música, saúde e espiritualidade. Mundo Saúde, 31(2), 290-6. http://www.sao camilo-sp.br/pdf/mundo_saude/53/17_Reflexoes.pdf

Leão, E. R., Puggina, A. C, Gatti, M. F. Z., Almeida, A. P., \& Silva, M. J. P. (2011). Música e enfermagem: Um recurso integrativo. In L. F. Salles \& M. J. P. Silva (Orgs.), Enfermagem e as práticas complementares em saúde (pp. 155-174). São Caetano do Sul, SP:Yendis.

Minayo, M. C. S. (2008). O desafio do conhecimento: pesquisa qualitativa em saúde (11a ed.). São Paulo, SP: Hucitec.

Munroe, S., \& Mount, B. (1978). Music therapy in palliative care. CMA Journal, 119(4), 1129-1134. https://www.cmaj.ca/ content/119/9/1029

Nuki, M., Yoshiuchi, K. M. D., \& Nomura, S. M. (1999). Effects of healing music on endocrinological changes. Proceedings of the World Congress for Music Therapy, 9, 124-135. http://www.musictherapyworld.org/ WFMT/2011_World_Congress_files/Proceedings\%20Washington\%20D.C_1999.pdf\#page=141

Oliveira, M. F., Oselame, G. B., Neves, E. B., \& Oliveira, E. M. (2014). Musicoterapia como ferramenta terapêutica no setordasaúde:Umarevisão sistemática. Revistada UniversidadeValedoRioVerde, 12(2),871-878.http:// periodicos. unincor.br/index.php/revistaunincor/article/view/1739

Petersen, E. M. (2012). Buscando novos sentidos à vida: Musicoterapia em cuidados paliativos. Revista Hospital Universitário Pedro Ernesto, 11(2). https://www.e-publicacoes.uerj.br/index.php/revistahupe/article/view/8944

Petrovsky, D., Cacchione, P. Z., \& George, M. (2015). Review of the effect of music interventions on symptoms of anxiety and depression in older adults with mild dementia. International Psychogeriatrics, 27(10), 1661-1670. https://pubmed.ncbi.nlm.nih.gov/25921299/

Pinto, A. C., Marchesini, S. M., Zugno, P. I., Zimmermann, K. G., Dagostin, V. S., \& Soratto, M. T. (2015). A importância da espiritualidade em pacientes com câncer. Revista Saúde.Com, 11(2), 114-122. http://periodicos2.uesb.br/ index.php/rsc/article/view/351

Ruud, E. (1998). Music therapy: Improvisation, communication and culture. Gilsum: Barcelona Publishers.

Sales, C. A. (2011). A música na terminalidade humana: Concepções dos familiares. Revista da Escola de Enfermagem da USP, 45(1), 138-145. https://www.scielo.br/pdf/reeusp/v45n1/19.pdf

Sales, C. A., Silva, V. A., Pilger, C., \& Marcon, S. S. (2011). A música na terminalidade humana: Concepções dos familiares. Revista da Escola de Enfermagem da. USP, 45(1), 138-145. http://www.scielo.br/pdf/reeusp/ v45n1/19.pdf

Santos, E. A., Zanini, C. R. O., \& Esperidião, E. (2015). Cuidando de quem cuida: uma revisão integrativa sobre a musicoterapia como possibilidade terapêutica no cuidado ao cuidador. Revista Música Hodie, 15(2), 92-104. https://www.revistas.ufg.br/musica/article/view/39740

Silva, V.A., Marcon, S. S., \& Sales, C. A. (2014). Percepções de familiares de pessoas portadoras de câncer sobre encontros musicais durante o tratamento antineoplásico. Revista BrasileiradeEnfermagem, 67(3).https://www.scielo.br/ pdf/reben/v67n3/0034-7167-reben-67-03-0408.pdf

Silva, V. A., \& Sales, C. A. (2013). Musical meetings as a resource in oncologic palliative care for users of a support homes. Revista da Escola de Enfermagem da USP, 47(3), 626-33. https://www.scielo.br/scielo. php?pid=S0080-62342013000300626\&script=sci_abstract

Souza, L. P. M., Forgione, M. C. R., \& Alves, V. L. R. (2000). Técnicas de relaxamento no contexto da psicoterapia de pacientes com queixas de dor crônica e fibromialgia: Uma proposta. Acta Fisiátrica, 7(2), 56-60. http://www.revistas.usp.br/actafisiatrica/article/view/102257

Turato, E. R. (2003). Tratado da metodologia da pesquisa clínico-qualitativa: Construção teórico-epistemológica, discussão comparada e aplicação nas áreas da saúde e humanas (2a ed.). Petrópolis, RJ: Vozes.

Zanetti, C.E. (2008). OAcompanhamento terapêutico no hospital geral:Música e psicologia aplicada à saúde. Revista da SBPH, 11(1), 50-59. http://pepsic.bvsalud.org/scielo.php?script=sci_arttext\&pid=S1516-08582008000100005 


\section{Natalia Schopf Frizzo}

Psicóloga clínica no Hospital de Clínicas de Porto Alegre (HCPA) e na Oncotrata Clínica Médica; Mestra em Psicologia e Saúde (UFCSPA); Especialista em Cuidados Paliativos (Albert Einstein/SP); Especialista em Gestão e Atenção Hospitalar - área de concentração: oncologia-hematologia (UFSM); Especialista em Psicologia Hospitalar (CFP), Porto Alegre - RS. Brasil.

E-mail: natalia.frizzo@oncotrata.com.br

(1) http:// orcid.org/0000-0001-9208-8035

\section{Anaí Zubik Camargo de Souza}

Psicóloga Clínica; Mestre em Comunicação (PUCRS); Especialista em Intervenções em Situações de Luto (CEFI), Porto Alegre - RS. Brasil.

E-mail: anaizubik@gmail.com

(1) http://orcid.org/0000-0002-6884-6075

\section{Ana Paula Wernz da Cunha Muller}

Médica Mastologista; doutora em Patologia Mamária (UFCSPA); Diretora médica na Oncotrata Clínica Médica, Porto Alegre - RS. Brasil.

E-mail: apmuller@terra.com.br

(1) http://orcid.org/0000-0002-1919-7152

\section{Adriana Mesquita Ozi}

Psicóloga clínica; Especialista em Gestão Estratégica de Pessoas (PUCRS), Porto Alegre -RS. Brasil.

E-mail: adriana.ozi@acad.pucrs.br

(1) http://orcid.org/0000-0003-4564-6078

Endereço para envio de correspondência:

Oncotrata Clínica Médica. Avenida Plinio Brasil Milano, 80, Bairro Higienópolis. CEP: 90520-002.

Porto Alegre - RS. Brasil.

Recebido $11 / 12 / 2018$

Aceito 15/06/2020

Received $11 / 12 / 2018$

Approved 15/06/2020

Recibido 11/12/2018

Aceptado 15/06/2020

Como citar: Frizzo, N. S., Souza, A. Z. C., Muller, A. P. W. C., \& Ozi, A. M. (2020). Música como recurso de enfrentamento em pacientes oncológicos e familiares. Psicologia: Ciência e Profissão, 40, 1-15.

https://doi.org/10.1590/1982-3703003217577

How to cite: Frizzo, N. S., Souza, A. Z. C., Muller, A. P. W. C., \& Ozi, A. M. (2020). Music as Resource of Coping for Oncology Patients and their Relatives . Psicologia: Ciência e Profissão, 40, 1-15.

https://doi.org/10.1590/1982-3703003217577

Cómo citar: Frizzo, N. S., Souza, A. Z. C., Muller, A. P. W. C., \& Ozi, A. M. (2020). Música como Recurso de Enfrentamiento en Pacientes Oncológicos y sus Familiares . Psicologia: Ciência e Profissão, 40, 1-15.

https://doi.org/10.1590/1982-3703003217577 